\title{
Analisis Portofolio Syariah Optimal Menggunakan Model Mean Variance Efficient Portofolio (MVEP) Dengan Pendekatan Data Envelopment Analysis (DEA)
}

\author{
Laeli Nurani dan Mohammad Farhan Qudratullah \\ Program Studi Matematika, Fakultas Sains dan Teknologi, Universitas Islam Negeri Sunan Kalijaga \\ Yogyakarta, Jl. Marsda Adisucipto Yogyakarta 55281
}

Korespondensi ditujukan kepada Laeli Nurani; Email: lelinurani@gmail.com

\begin{abstract}
Abstrak
Penelitian ini membahas analisis portofolio syariah optimum menggunakan model Mean-Variannce Efficient Portofolio (MVEP) yang proses pemilihan sahamnya menggunakan Data Envelopment Analysis (DEA) dengan menggunakan kendala input (Standar Deviasi, Debt Earning Ratio, Book Value Share, Price Book Value Ratio) dan kendala output (Return, Earning Per Share, Return On Equity, Return On Asset, Net Profit Margin, Price Earning Ratio). Data yang digunakan dalam Tugas Akhir ini adalah saham-saham yang terdaftar di Jakarta Islamic Index (JII) periode 27 Juni 2014 - 18 Februari 2016. Hasil uji efisiensi dengan DEA-CCR dan DEA-BCC diperoleh 14 saham terpilih sebagai kandidat pembentuk portofolio, yaitu: ADRO, ASRI, BSDE INDF, INTP, ITMG, KLBF, LPKR, LSIP, PGAS, SMGR, SMRA, TLKM, dan UNVR. Dari ke-14 saham tersebut diperoleh 4 saham optimal dengan besar dana yang harus diinvestasikan pada masing-masing saham yaitu: TLKM $(52 \%)$, UNVR (7\%), LPKR (17\%) dan INDF $(24 \%)$ dengan ekspektasi keuntungan sebesar $0,000646(0,06 \%)$ resiko sebesar $0,01389(1,4 \%)$.
\end{abstract}

Kata Kunci: Data Envelopment Analysis (DEA), Mean Variance Efficient Portofolio (MVEP), Portofolio Syariah.

\begin{abstract}
This study discusses the analysis of a portfolio of Shariah optimum use models Mean-Variannce Efficient Portfolio (MVEP) that the process of selecting shares using Data Envelopment Analysis (DEA) using constraint input (Standard Deviation, Debt Earning Ratio, Book Value Share, Price Book Value Ratio) and output constraints (Return, Earning Per Share, Return on Equity, Return on Assets, Net Profit Margin, Price Earning Ratio). The data used in this final project is a stock-shares listed on the Jakarta Islamic Index (JII) in the period June 27, 2014 - February 18, 2016. The result of the efficiency with DEA-CCR and DEA-BCC acquired 14 shares selected as a candidate for forming the portfolio, namely: ADRO, ASRI, BSDE INDF, INTP, ITMG, KLBF, LPKR, LSIP, PGN, SMGR, SMRA, TLKM, and UNVR. Of the 14 shares gained 4 shares optimal much money should be invested in each stock, namely: TLKM $(52 \%)$, UNVR $(7 \%)$, LPKR $(17 \%)$ and INDF $(24 \%)$ with expectations of a gain of $0.000646(0.06 \%)$ risk of 0.01389 $(1.4 \%)$.
\end{abstract}

Keywords: Data Envelopment Analysis (DEA), Mean Variance Efficient Portofolio (MVEP), Portfolio Sharia.

\section{Pendahuluan}

Seorang investor sangat mengharapkan keuntungan (return) yang besar dengan kerugian (risk) seminimum mungkin. Oleh sebab itu, return dan risk perlu diseimbangkan dengan produk-produk dimana investorberinvestasi, sehingga investor tidak mengalami kerugian yang terlalu parah ketika salah satu atau beberapa investasinya merugi. Investor sangat dianjurkan untuk tidak hanya menginvestasikan asetnya kedalam satu saham saja, karena jika saham tersebut merugi investor tidak akan mendapatkan keuntungan sedikitpun. Oleh karena itu, perlu dilakukan analisis terhadap harga saham dan diperlukan suatu portofolio optimal. Tujuan dari portofolio optimal tersebut salah satunya ialah investor dapat mengetahui saham-saham yang memiliki potensi untuk menjadi saham dengan keuntungan yang maksimal dengan kerugian seminimum mungkin, sehingga tidak merugikan investor. 
Pendekatan yang dapat digunakan untuk memilih saham efisien dalam pembentukan portofolio adalah Data Envelopment Analysis (DEA) [6].

DEA merupakan metodologi non parametrik yang didasarkan pada linear programming dan digunakan untuk menganalisis fungsi produksi melalui suatu pemetaan frontier produksi, Anderson (2004). DEA merupakan satu dari sekian banyak jenis pendekatan yang dilakukan dalam portofolio saham, DEA dipilh karena dalam pendekatan DEA tidak memerlukan hubungan fungsi tertentu antara output dan input produksi ataupun asumsi dari distribusi tertentu. DEA memperbolehkan penggunaan multiple input dan multiple output, DEA juga menghasilkan informasi detail nilai efisiensi unit yang lebih spesifik yang dapat dijadikan perbandingan dalam memilih saham yang efisien.Setelah terpilih beberapa saham yang efisien selanjutnya digunakan metode Mean Variance Efficient Portofolio (MVEP) untuk memilih saham yang akan diinvestasikan oleh investor. MVEP merupakan konsep portofolio efisien Markowitz. Maruddani dan Purbowati (2009) mendefinisikan Mean Variance Efficient Portofolio (MVEP) sebagai portofolio yang memilliki varian minimum diantara keseluruhan kemungkinan portofolio yang dapat dibentuk [4].

Pada tulisan ini digunakan pendekatan Data Envelopment Analysis (DEA) dengan orientasi output untuk menentukan saham-saham yang efisien, sehingga dapat dijadikan pertimbangan dalam pembentukan portofolio. Metode yang digunakan yaitu Mean Variance EfficientPortofolio (MVEP).

\section{Landasan Teori}

\section{Pasar Modal}

Pasar modal merupakan tempat dimana berbagai pihak khususnya perusahaan menjual saham (stock) dan obligasi (bond) dengan tujuan dari hasil penjualan tersebut nantinya akan dipergunakan sebagai tambahan dana atau untuk memperkuat perusahaan [9].

\section{Return dan Risk}

Return merupakan keuntungan yang diperoleh oleh perusahaan, individu dan institusi dari hasil kebijakan investasi yang dilakukannya. Adapun menurut R.J. Shook return merupakan laba investasi, baik melalui bunga ataupun deviden [2] [11].

Return Saham Individual atau return realisasian merupakan

$$
\begin{gathered}
R_{i 1}=\frac{P_{i t}-P_{i t-1}}{P_{i t-1}} \\
R_{t}=\ln \left(\frac{P_{t}}{P_{t-1}}\right)=\ln \left(P_{t}\right)-\ln \left(P_{t-1}\right)
\end{gathered}
$$

Dengan:

$R_{i 1} \quad=$ Return saham i periode $\mathrm{t}$

$P_{i t} \quad=$ Harga saham i periode $\mathrm{t}$

$P_{i 1-1}=$ Harga saham $\mathrm{i}$ periode $\mathrm{t}-1$

$\sigma_{i}^{2} \quad=$ Variansi

Menurut Joel G.Siegel dan Jae K.Shim risiko merupakan proses pengukuran dan penganalisian risiko disatukan dengan keputusan keuangan dan investasi.

$$
\sigma_{i}^{2}=\frac{\sum_{t=1}^{n}\left(R_{i \dagger}-E\left(R_{i}\right)\right)^{2}}{N}
$$




\section{Program Linear}

Pemrograman linier merupakan suatu pemrograman matematik yang di dalamnya terdapat fungsi objektif berbentuk linier yang tidak diketahui dan fungsi-fungsi kendala yang berbentuk persamaan linier ataupun ketidaksamaan linier [10].

Bentuk umum persamaaan linear untuk fungsi tujuan maksimum, yaitu:

$$
f\left(x_{1}, x_{2}, \ldots, x_{n}\right)=\mathrm{Z}=\sum_{j=1}^{n} c_{j} x_{j}
$$

Dengan kendala:

$\sum_{j=1} a_{i} x_{j}=b_{i} \quad$ untuk $i=1,2,3, \ldots, m$

$x_{j} \geq 0$ untuk $j=1,2,3, \ldots, n$

Dimana $c_{j}, b_{i}, a_{i}$, diketahui kostant.

Begitupun dengan fungsi kendala minimum, sama seperti fungsi maksimum, hanya saja fungsi tujuan minimum dan batas kendala kurang dari sama dengan $\left(\leq b_{i}\right)$.

\section{Data Envelopment Analysis (DEA)}

Data envelopment analysis (DEA) merupakan suatu metodologi yang digunakan untuk mengevaluasi efisiensi dari suatu unit pengambilan keputusan (unit kerja) serta menggunakan sejumlah input untuk memperoleh suatu output yang ditargetkan. Terdapat 2 model DEA, yaitu DEA Charnes, Chooper dan Rhores (DEA-CCR) dan DEA Banker, Charnes, Chooper (DEA-BCC) [4], [7], [11].

- Model DEA CCR

Fungsi tujuan: Maks $\theta$

$$
\begin{aligned}
& \theta=\frac{u_{1} y_{1 k}+u_{2} y_{2 k}+\cdots+u_{s} y_{s}}{1} \leq 1(j=1,2, \ldots n) \\
& \theta=u_{1} y_{1}+u_{2} y_{2 k}+\cdots+u_{s} y_{s 0} \leq 1(j=1,2, \ldots n)
\end{aligned}
$$

Kendala:

$$
\begin{aligned}
& v_{1} x_{1 k}+\cdots+v_{m} x_{m}=1 \\
& u_{1} y_{1 j}+\cdots+u_{s} y_{s} \leq v_{1} x_{1 j}+\cdots+v_{m} x_{m} \quad(j=1,2, \ldots, n) \\
& v_{1}, v_{2}, \ldots, v_{m} \geq 0
\end{aligned}
$$

- Model DEA BCC

Dengan demikian persamaan model BCC untuk orientasi output:

$$
Z=\max \theta
$$

Kendala:

$$
\begin{aligned}
& x_{o}-\sum_{j=1}^{n} x_{i} \lambda_{j} \geq 0, i=1,2, \ldots, m \\
& \sum_{j=1}^{n} y_{j} \lambda_{j}-\theta y_{o} \geq 0, r=1,2, \ldots, s \\
& \sum_{j=1}^{n} \lambda_{j}=1 \\
& \lambda_{j} \geq 0, j=1,2, \ldots n
\end{aligned}
$$


Keterangan:

$$
\begin{aligned}
\theta & =\text { Efisiensi model CCR } \\
n & =\text { Jumlah DMU } \\
m & =\text { Jumlah input } \\
s & =\text { Jumlah output } \\
x_{i} & =\text { Nilai input ke-i dari DMU } \\
y_{r} & =\text { Nilai output ke-r DMUj } \\
\lambda_{j} & =\text { Bobot DMUj untuk DMU yang dihitung bobot }
\end{aligned}
$$

\section{Mean Variance Efficient Portofolio (MVEP)}

Portofolio mean-varians meminimalkan risiko berdasarkan tingkat expected return portofolio tertentu, sehingga secara matematis, portofolio metode mean-varians Markowitz dapat diformulasikan sebagai berikut [5], [6]:

$$
\text { Minimize: } \sum_{i=1}^{n} \sum_{j=1}^{m} w_{i} w_{j} \sigma_{i}
$$

Dengan kendala sebagai berikut:

$$
\begin{aligned}
& \sum_{i=1}^{n} w_{i} r_{i}=R_{p} \\
& \sum_{i=1}^{n} w_{i}=1 \\
& 0 \leq w_{i} \leq 1, i=1, \ldots, n
\end{aligned}
$$

\section{Hasil dan Pembahasan}

\section{Analisis Deskriptif}

Data awal yang digunakan dalam penelitian ini adalah nilai return, resiko (standar deviasi), beserta nilai rasio keuangan seperti: ROA, ROE, BV, PBV, DER, PER, EPSserta NPM pada masing-masing saham yang tergabung dalam saham gabungan Jakarta Islamic Index (JII) periode 27 Jni 201418 Februari 2016. Data tersebut nantinya akan dikelompokan ke dalam variabel inputdan Output. Pada penelitian ini variabel input yang disertakan yaitu standar deviasi, DER (Debt to Equity Ratio), BV (Book Value), PBV (Price Book Value). Variabel output yang disertakan yaitu Return, (Return On Asset) ROA, (Return on Equity) ROE, (Net Provit Margin) NPM, (Earning Per Share) EPS, (Price Earning Ratio) PER.

\section{Pengujian Data Envelopmnet Analysis (DEA)}

Selanjutnya diuji DEA (tabel 1) untuk mengetahui saham-saham efisien yang nantinya digunakan untuk pembobotan saham portofolio.

Tabel 1 Hasil Menggunakan DEAP versi 2.1.

\begin{tabular}{crrrc}
\hline No & Kode & TE CRS & TE VRS & SE \\
\hline 1 & AALI & 0.762 & 0.967 & 0.789 \\
2 & ADRO & 1.000 & 1.000 & 1.000 \\
3 & AKRA & 0.866 & 0.866 & 0.995 \\
4 & ASII & 0.942 & 0.999 & 0.942 \\
5 & ASRI & 1.000 & 1.000 & 1.000 \\
6 & BSDE & 1.000 & 1.000 & 1.000 \\
7 & ICBP & 0.940 & 1.000 & 0.940 \\
8 & INDF & 1.000 & 1.000 & 1.000
\end{tabular}




\begin{tabular}{ccccc}
9 & INTP & 1.000 & 1.000 & 1.000 \\
10 & ITMG & 1.000 & 1.000 & 1.000 \\
11 & KLBF & 1.000 & 1.000 & 1.000 \\
12 & LPKR & 1.000 & 1.000 & 1.000 \\
13 & LSIP & 1.000 & 1.000 & 1.000 \\
14 & MPPA & 0.833 & 0.999 & 0.834 \\
15 & PGAS & 1.000 & 1.000 & 1.000 \\
16 & SMGR & 1.000 & 1.000 & 1.000 \\
17 & SMRA & 1.000 & 1.000 & 1.000 \\
18 & TLKM & 1.000 & 1.000 & 1.000 \\
19 & UNTR & 0.998 & 1.000 & 0.998 \\
20 & UNVR & 1.000 & 1.000 & 1.000 \\
21 & WIKA & 0.813 & 1.000 & 0.813 \\
\hline
\end{tabular}

Berdasarkan (tabel 1) didapat 14 saham terpilih, diantaranya: ADRO, ASRI, BSDE, INDF, INTP, ITMG, KLBF, LPKR, LSIP, PGAS, SMGR, SMRA, TLKM, dan UNVR. Kemudian saham terpilih ini akan dihitung nilai proporsi sahamnya untuk mengetahui berapa besar kemungkinan return dan resiko yang akan didapatkan oleh investor.

\section{Pemilihan Portofolio}

Saham efisien yang telah diperoleh selanjutnya dikelompokan kedalam 4 kategori saham dengan return dan resiko sebagai berikut:

Tabel 2 Return dan Resiko Portofolio.

\begin{tabular}{crrr}
\hline No & Kode & Return & Stdev \\
\hline 1 & ADRO & $-0,0011$ & 0,02974 \\
2 & ASRI & $-9,00 \mathrm{E}-05$ & 0,02589 \\
3 & BSDE & 0,00077 & 0,02366 \\
4 & INDF & 0,00025 & 0,02189 \\
5 & INTP & $-3,00 \mathrm{E}-05$ & 0,02397 \\
6 & ITMG & $-0,0035$ & 0,02645 \\
7 & KLBF & $-0,0004$ & 0,01959 \\
8 & LPKR & 0,0005 & 0,02257 \\
9 & LSIP & $-0,0008$ & 0,02571 \\
10 & PGAS & $-0,0014$ & 0,02357 \\
11 & SMGR & $-0,0006$ & 0,02296 \\
12 & SMRA & $-0,0005$ & 0,02751 \\
13 & TLKM & 0,00083 & 0,01427 \\
15 & UNVR & 0,00097 & 0,01817 \\
\hline
\end{tabular}

Berdasarkan tabel 2 di atas dipilih saham yang memiliki return positif sebagai saham pembentuk portofolio, INDF, TLKM, LPKR, BSDE dan UNVR.

\section{Proporsi Dana dengan Metode Mean Variance Efficient Portofolio (MVEP)}

Untuk mendapatkan besarnya nilai mean return dan risiko portofolio, maka akan dicari besarnya proporsi dari masing-masing saham portofolio. Pembobotan proporsi portofolio optimal didasarkan pada rumus [5]: 


$$
w=\frac{\sum^{-1} 1_{N}}{1_{N}^{T} \Sigma^{-1} 1_{N}}
$$

Dengan $\Sigma^{-1}$ menyatakan invers matriks varians kovarians $\mathrm{N} \times \mathrm{N}$ dan $1_{N}$ menyatakan vektor dengan elemen 1 sebanyak $N$.

Berikut merupakan proporsi dana saham untuk kategori portofolio yang nilai returnnya bernilai positif (0). Saham BSDE tidak disetakan karena memiliki nilai proporsi negatif.

Tabel 3 Nilai Proporsi Dana.

\begin{tabular}{ccc}
\hline Saham & Nilai & Proporsi \\
\hline TLKM & 0.5207 & $52,07 \%$ \\
UNVR & 0.0703 & $7,03 \%$ \\
LPKR & 0.1728 & 17,285 \\
INDF & 0.2363 & $23,63 \%$ \\
\hline
\end{tabular}

\section{Return dan Resiko Portofolio}

Untuk menghitung besar keuntungan dan kerugian dapat dilakukan dengan cara mengalikan jumlah komposisi dengan nilai return yang diperoleh oleh masing-masing saham. Kemudian hasil dari perkalian beberapa saham tersebut dijumlahkan tiap barisnya, kemudian hasil rata-rata dan standar deviasi dari penjumlahan itulah yang disebut sebagai return da resiko portofolio yang nantinya dikalikan dengan jumlah nominal uang yang akan diinvestasikan oleh investor.

Secara matematis dapat dituliskan sebagai berikut:

$$
\text { Nilai saham }=(\text { Nilai komposisi) }(\text { nilai retun ke- } i)
$$

Sedangkan untuk menjumlahkan saham-saham disetiap kategori portofolio, yaitu:

$$
\text { Jumlah saham }=\sum_{i=1}^{n} n \quad s \text { ha }
$$

Dari rumus diatas, dapat diperoleh niali return dan resiko dari 5 saham portofolio, sebagai berikut:

Tabel 3 Jumlah Return dan Resiko Saham.

\begin{tabular}{rrrr}
\hline Saham & Return & Resiko & Rasio \\
\hline TLKM,UNVR,LPKR dan INDF & 0,000646 & 0,013289 & 0,048631 \\
\hline
\end{tabular}

Jadi Investor akan mendapatkan keuntungan sebesar 0,000646, resiko sebesar 0,01389 dan rasio 0,048631 sehingga apabila seorang investor menginvestasikan uangnya sebesar Rp. 10.000.000 investor akan mendapatkan rasio (keuntungan/resiko) sebesar Rp. 486.308,9

\section{Kesimpulan}

Berikut adalah beberapa kesimpulan yang direkomendasikan dari peneliti ini adalah:

a. Dari analisis efisiensi dengam menggunakan metode Data Envelopment Analysis (DEA) diperoleh saham yang efisien, yaitu: ADRO, ASRI, BSDE, INDF, INTP, ITMG, KLBF, LPKR, LSIP, PGAS, SMGR, SMRA, TLKM dan UNVR

b. Portofolio yang optimal yaitu portofolio yang terdiri dari TLKM (52\%), UNVR (7\%), LPKR (17\%) dan INDF $(24 \%)$ dengan ekspektasi keuntungan sebesar $0,000646(0,06 \%)$ resiko sebesar 0,01389 $(1,4 \%)$. 


\section{Referensi}

[1] Anton, Howard. 1988. Dasar- dasar aljabar linier. Jakarta : Karisma publishing.

[2] Arisma, Elok. 2014. Perbandingan optimisasi portofolio model Mean Varian dengan Tail Mean Varian. Fakultas Satistika.Universitas Gajah Mada Yogyakarta.

[3] Chiang, Alpha C. 2005. Dasar-dasar Matematika Ekonomi . Jakarta : Erlangga. Cooper, W.W., Lawrence M. Seiford, and Kaoru Tone. 2007. Introduction toData Envelopment Analysis and Its Uses:With DEA Solver Software and References. Spring Science+Busines Media, LLC.

[4] Cooper, W.W., Lawrence M. Seiford, and Kaoru Tone. 2007. Data Envelopment Analysis: A Comprehensive Text with Models, Applications, Reference and DEA-Solver Sofware, 2nd en. Spring Science+Busines Media, LLC.

[5] Dwi Sila Sakti, Hartatun. 2014. Pembentukan Portofolio Menggunakan mean Variance Dan Peramalan Harga Saham Menggunakan Metode Single Moving Average. Fakultas Sains dan Tekhnologi. UIN Sunan Kalijaga Yogyakarta.

[6] Fahmi, Irham. 2009. Teori portofolio dan Analisis Investasi: Teori Soal Jawab. Bandung: Alfa Beta.

[7] Ferdinan Leto, Ernest. Efisiensi Psiensi Perbankan dengan Menggunakan Data Envelopment Analysis (DEA). Jurnal FMIPA Universitas Brawijaya.

[8] Gudono, 2014. Analisis Data Multivariat Edisi 3. Yogyakarta : BPFE

[9] Jogiyanto. 2003. Analisis Investasi dan Teori Portofolio. Yogyakarta: Gajah Mada Press.a

[10] Kakiay, Thomas j. 2008. Pemrograman Linier : metode dan Problema. Yogyakarta : Andi

[11] Prasetyo, Fuad. 2015. Analisis Portofolio Optimal Model Indeks Tunggal dengan Pendekatan Data Envelopment Analysis (DEA). Fakultas Sains dan Tekhnologi. UIN Sunan Kalijaga Yogyakarta. 